\title{
Electrodeposition of Diamond-like Carbon (DLC) Films on Mg by Plasma Electrolysis
}

\section{Chaolei BAN, * Baoxu HUANG, Changzheng WANG, Liping WANG, and Xin SHAO}

School of Materials Science and Engineering, Liaocheng University, Liaocheng 252059, China

* Corresponding author: banchaolei@163.com

\begin{abstract}
Diamond-like carbon (DLC) films were deposited on $\mathrm{Mg}$ substrate in $\mathrm{CH}_{3} \mathrm{OH}$ and $\mathrm{KNO}_{3}$ solution by the liquid-phase electrodeposition technique at ambient pressure and temperature. The applied voltage between the electrodes was low $(130 \mathrm{~V})$ due to the use of conductive inorganic liquids. The surface morphology was examined by Scanning Electron Microscopy (SEM). Corrosion performance of the films was investigated by potentiodynamic polararization tests and electrochemical impedance spectroscopy (EIS) in $3.5 \% \mathrm{NaCl}$ solution. The structure of the films was characterized by X-ray photoelectron spectroscopy (XPS) and Raman spectroscopy. Raman spectroscopy analysis of the films revealed two broad bands at approximately 1369.5 and $1554.7 \mathrm{~cm}^{-1}$, relating to D and G-band of typical $D L C$ film, respectively. The low intensity ratio of $I_{D} / I_{G}$ indicate that the DLC films have a high ratio of $\mathrm{sp}^{3}$ to $\mathrm{sp}^{2}$ bonding, which is also in accordance with the results of XPS spectra. SEM showed that DLC film was uniform, homogeneous but rough. Potentiodynamic polarization curve and EIS indicated the corrosion resistance of the Mg substrate was markedly improved by DLC films. A mechanism for the formation of $\mathrm{sp}^{3}$ and $\mathrm{sp}^{2}$ hybridizations is proposed.
\end{abstract}

(C) The Electrochemical Society of Japan, All rights reserved.

Keywords : Electrodeposition, Diamond-like Carbon, Corrosion, Micro-arc Discharge

\section{Introduction}

Magnesium alloys have been widely used as structural materials in the automotive, aerospace and communication industries, as well as for orthopedic implants, because of their low density, high strength to weight ratio, high dimensional stability, good electromagnetic shielding and damping characteristics, and good machining and recycling ability. ${ }^{1-6}$ However, magnesium alloys also have some drawbacks such as low fatigue strength and poor wear and corrosion resistance, which restrict their more extensive application. ${ }^{7,8}$ Considerable effort has been made to improve the wear and anti-corrosion properties of magnesium alloys. Several surface modification techniques ${ }^{9-13}$ including chemical conversion, anodic oxidation, microarc oxidation (MAO) treatment, electroplating, electroless plating and physical vapor deposition (PVD), have been used to protect the surface of magnesium alloys.

The unique combination of outstanding physical and chemical properties of diamond-like carbon (DLC) films, such as high hardness and wear resistance, low friction coefficient, and chemical inertness, makes it a very attractive candidate for surface protective coatings to improve both the wear and corrosion resistance of magnesium alloys. ${ }^{14}$ Dai et al. showed that Cr-incorporated DLC protective coatings with high adhesion strength and good wear resistance could be applied to magnesium alloys. ${ }^{15}$ Choi et al. investigated the protective ability of DLC coatings on AZ31 magnesium alloy in aqueous $\mathrm{NaCl}$ solution. ${ }^{16}$ However, the above DLC coatings are deposited by traditional techniques such as PVD, CVD, ion-beam method, laser processing, etc., which necessitate a complex machine system. In this paper a simple method to prepare DLC films by micro-arc discharge (MAD) was reported. The MAD in an aqueous solution, which is also called plasma electrolysis, has been utilized to ionize media from the solution so that complex compounds are synthesized on the metal surface through the plasma chemical interactions. ${ }^{17-19}$ It is expected that the corrosion properties of magnesium alloys will be enhanced by such easily approach.

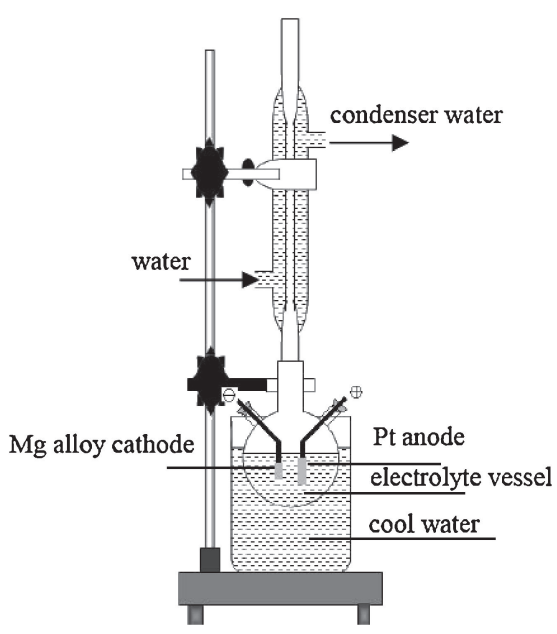

Figure 1. A schematic outline of the MAD system.

\section{Experimental details}

DLC films were synthesized by MAD in an aqueous solution containing $50 \mathrm{vol} \% \quad 0.25 \mathrm{~mol} \mathrm{~L}^{-1} \quad \mathrm{KNO}_{3}$ aqueous solution and $50 \mathrm{vol} \%$ methanol. Figure 1 showed a schematic outline of the MAD system. The cathode was a mechanically polished and polished AZ31 Mg alloy plate with a surface area of $30 \mathrm{~mm}^{2}$. The anode was a Pt plate with an area of $60 \mathrm{~mm}^{2}$. The distance between electrodes was $15 \mathrm{~mm}$. The DC voltage applied to the electrodes was $130 \mathrm{~V}$; the variation in current in the MAD process was monitored by a digital multimeter connected to a PC system; the deposit time was $0.5 \mathrm{~h}$. The electrolyte vessel was immersed in a big cooling water bath and connected with a condenser to keep the temperature constant and to avoid the solution from evaporation. Field emission scanning electron microscope (SEM, FEI, sirion200), Raman 


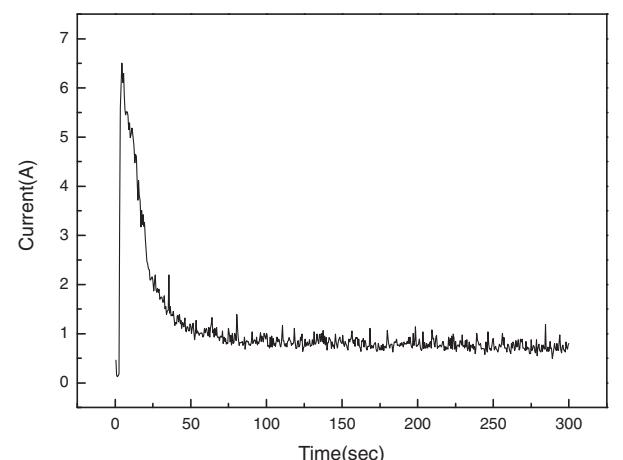

Figure 2. Current transients for film deposition at $130 \mathrm{~V}$.

Spectroscopy (Renishaw, RM2000) and X-ray photo-electron of $284.8 \mathrm{eV}$ has been assumed for this purpose. Background subtraction was performed using the Shirley method. The operating voltage of the SEM is $10 \mathrm{kV}$. Raman spectroscopy was working at a wavelength of $514.5 \mathrm{~nm}$ and the power is about $4.7 \mathrm{~mW}$. The vacuum of the XPS using monochromated $\mathrm{AlK} \alpha \mathrm{X}$-rays is $6.7 \times 10^{-8} \mathrm{~Pa}$, and the energy resolution is $0.5 \mathrm{eV}$.

The corrosion resistance of the coated and uncoated samples was evaluated by potentiodynamic polarization and electrochemical impedance spectroscopy (EIS) with a galvano-chemistry Workstation (CHI660C, Shanghai) in $3.5 \% \mathrm{NaCl}$ solution at room temperature. A saturated calomel electrode (SCE) was used as reference and a Pt foil served as the auxiliary electrode. The polarization curves were obtained with a sweep rate of $0.1 \mathrm{mV} / \mathrm{s}$. The EIS spectra were obtained over the frequency range $10 \mathrm{mHz}-$ $100 \mathrm{kHz}$ with an applied AC perturbation potential of $10 \mathrm{mV}$ amplitude. The EIS data were interpreted on the basis of an equivalent circuit determined using a suitable fitting procedure described in Zsimpwin software.

\section{Results and Discussion}

The current transients for the samples deposited at $130 \mathrm{~V}$ on $\mathrm{Mg}$ substrate is shown in Fig. 2. During the film deposition, the current decreases from 6.5 to $1 \mathrm{~A}$ in approximately $50 \mathrm{sec}$ and then remains constant indicating that the growth rate saturates with time. This is also reported by other authors ${ }^{20}$ and should be related to the high film resistivity after a monolayer deposition, because the true solidliquid interface is not anymore a Mg-organic liquid interface but a DLC film-organic liquid interface.

Raman spectroscopy is an important method to characterize the bonding structure of DLC films, since at visible excitation it gives direct information on the $\mathrm{sp}^{2}$ bonding structure ( $\mathrm{G}$ line) and indirect information on the $\mathrm{sp}^{3}$ hybridized atoms (D line). Figure 3 showed the Raman spectrum of DLC films prepared in water methanol solution. The broad peak could be decomposed into the Gaussian centered at $1554.7 \mathrm{~cm}^{-1}$ (G line) $\mathrm{cm}^{-1}$ and at $1369.5 \mathrm{~cm}^{-1}$ (D line), respectively, and their intensity ratio $\left(I_{\mathrm{D}} / I_{\mathrm{G}}\right)$ was about 0.847 . Prawer et al. (1996) reported that the D peak occurred only from small graphites crystals and the $G$ peak resulted from lattice vibrations in the plane of the graphite-like rings. The intensity ratio $I_{\mathrm{D}} / I_{\mathrm{G}}$ reveals the ration of $\mathrm{sp}^{2} / \mathrm{sp}^{3}$ bond contents (Chen et al., 2002; Hauert, 2003). The spectrum in Fig. 3 possessed the most dominant characterizations of the typical DLC films, which confirmed the formation of DLC films on the Mg alloy cathode.

$\mathrm{X}$-ray Photoelectron Spectroscopy (XPS) is one of the standard methods for the determination of the $\mathrm{sp}^{2}$ and the $\mathrm{sp}^{3}$ fractions in amorphous carbon films. The $\mathrm{C} 1 \mathrm{~s}$ binding energy of the diamond and the graphite is slightly different, the bias is about $0.7-0.9 \mathrm{eV}$. Some researchers reported that the $\mathrm{C} 1 \mathrm{~s}$ binding energy of the

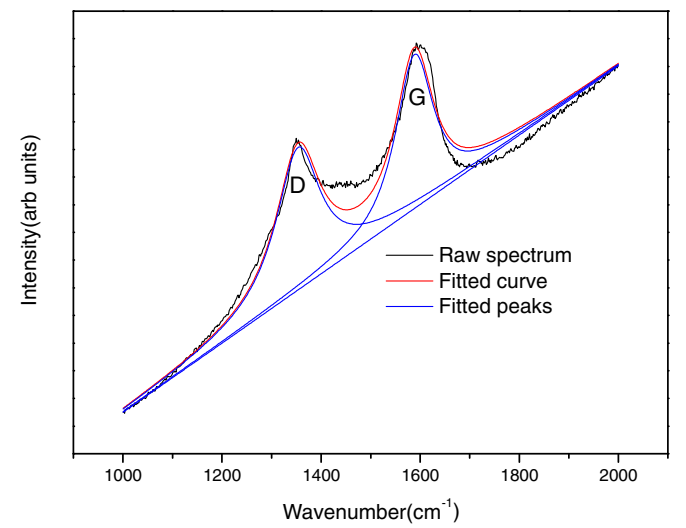

Figure 3. (Color online) Raman spectrum and its Gaussian center of DLC films prepared in water methanol solution.
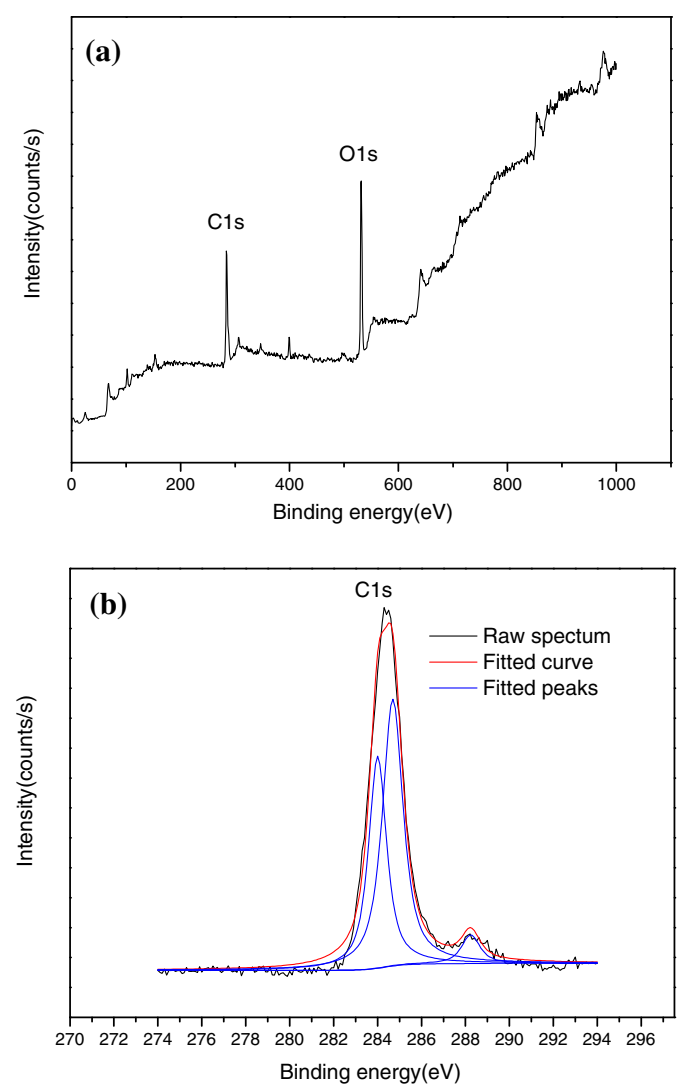

Figure 4. (Color online) The XPS spectra of DLC films prepared in water methanol solution and its $\mathrm{C} 1 \mathrm{~s}$ decomposition spectrum: (a) the XPS spectra, (b) decomposition spectrum $\mathrm{C} 1 \mathrm{~s}$.

graphite $\left(\mathrm{sp}^{2}\right)$ and the diamond $\left(\mathrm{sp}^{3}\right)$ was, respectively, 284.3 and $285.2 \mathrm{eV} .{ }^{19,20}$ The XPS of DLC film prepared in water ethanol solution was shown in Fig. 4(a), which presents peaks from $\mathrm{C} 1 \mathrm{~s}$ $(284.5 \mathrm{eV})$ and $\mathrm{O} 1 \mathrm{~s}(531.0 \mathrm{eV})$. The strong oxygen spectrum was attributed to the absorbed water (Lu and Chen, 1999), which may originate in the chamber or may have been present as impurity or constituent in the film. Furthermore, the C1s core peak may be deconvoluted into three peaks of graphite ( $\mathrm{sp}^{2}$ bond: $284.3 \mathrm{eV}$ ), diamond ( $\mathrm{sp}^{3}$ band: $285.2 \mathrm{eV}$ ) and $\mathrm{C}-\mathrm{O}$ bond $(287.6 \mathrm{eV})$, as shown in Fig. 4(b). The $\mathrm{C} 1 \mathrm{~s}$ core peaks are consistent with the values in the literature (Taki and Taki, 1998; Yan et al., 2004; Paik, 2005). The $\mathrm{sp}^{3}$ fraction of the DLC films was obtained in light of the ratio of the area of $\mathrm{sp}^{3} \mathrm{C} 1 \mathrm{~s}$ peak, and in the whole area of the $\mathrm{C} 1 \mathrm{~s}$ peak, it 

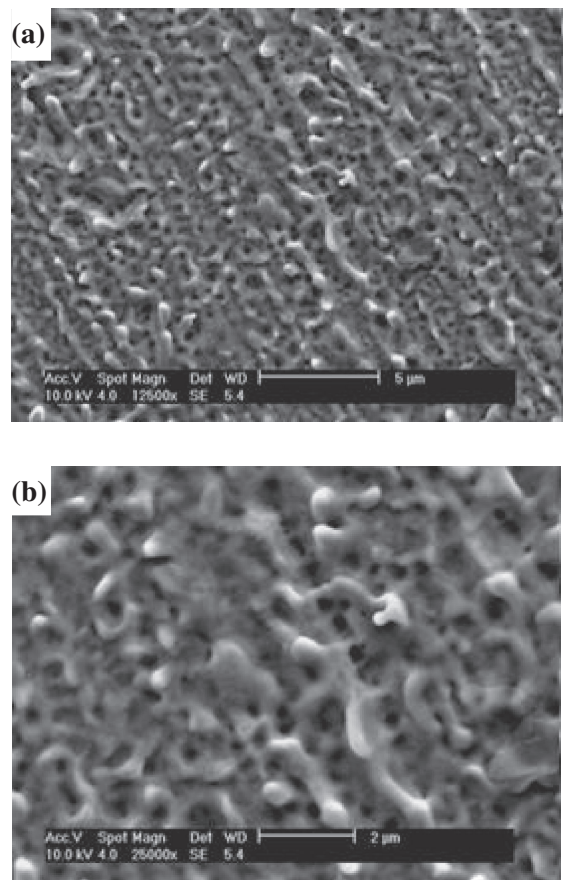

Figure 5. SEM morphologies of DLC films prepared in water ethanol solution: (a) a low magnitude and (b) a high magnitude SEM morphology of DLC films.

was about $54.1 \%$, which reveals that the film is associated with the dominance of diamond-like character, well consistent with the Raman result.

The SEM morphology of DLC films on Mg was shown in Fig. 5. The DLC films were quite uniform, but the surface looks rough due to the high impact force during micro-arc process. Compared with DLC films synthesized by unbalanced magnetron sputtering, the morphology of DLC synthesized by MAD was more uniform, homogeneous but rougher.

The electro-deposition chemical mechanism of carbon materials is not know, however some mechanisms have been proposed to describe diamond growth. A mechanism for this process using methanol or ethanol as organic electrolyte was proposed by He et al. and Tsukada et al. ${ }^{21,22}$ Inspired by their work and basing on the formation of gas products in the solution, we suggest the following formation mechanism of DLC film in this work.

Using methanol as the electrolyte there is a strong possibility that methanol molecules are polarized under an applied potential, as can be demonstrated by Eq. (1):

$$
\mathrm{CH}_{3}^{\delta+}-\mathrm{OH}^{\delta-} \rightarrow \mathrm{CH}_{3}^{\delta+} \ldots \mathrm{OH}^{\delta-}
$$

In the cathode (hydrogen-terminated magnesium surface), the molecule positive pole is bonded to the $\mathrm{Mg}$ surface by replacement of the hydrogen linked to the $\mathrm{Mg}$. Further, the ionization of methanol (loss of $\mathrm{OH}$ ) occurs by the attacking of hydrogen ion removed over the oxygen bonded to carbon. In the present case, the reaction is given in Eq. (2):

$$
\begin{aligned}
& \mathrm{CH}_{3}^{\delta+}-\mathrm{OH}^{\delta-} \stackrel{\equiv \mathrm{Mg}-\mathrm{H}}{\longrightarrow} \mathrm{CH}_{3(\text { Solution })}^{+}+\mathrm{H}_{2} \mathrm{O}+\equiv \mathrm{Mg}^{-} \\
& \mathrm{CH}_{3(\text { Solution })}^{+}+\equiv \mathrm{Mg}^{-} \rightarrow \equiv \mathrm{Mg}-\mathrm{CH}_{3(\text { Substrate })}
\end{aligned}
$$

In the cathode (substrate) the major step is the dehydrogenation of methyl that occurs via electrooxidation reaction [Eq. (3)]:

$$
\mathrm{CH}_{3}^{+}+e \rightarrow \mathrm{C}+3 / 2 \mathrm{H}_{2}
$$

A mechanism that can occur is the coupling of methyl groups over the substrate. In this case, methyl ions are inserted into the $\mathrm{C}-\mathrm{H}$
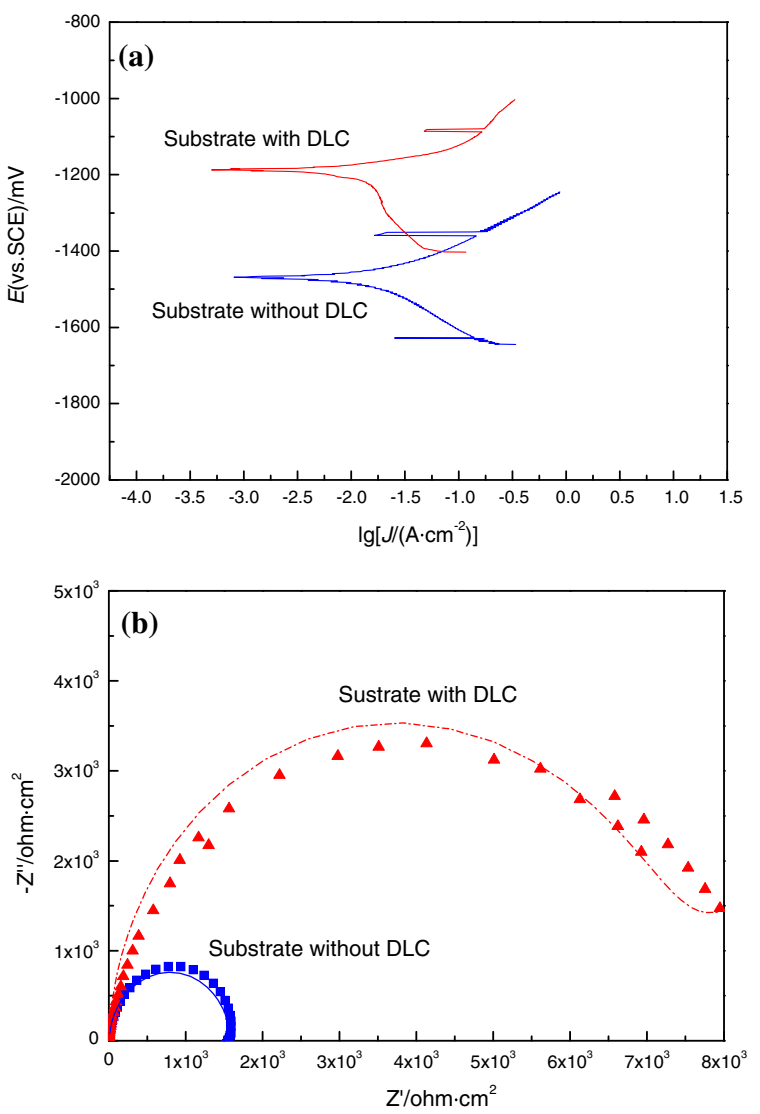

Figure 6. (Color online) Potentiodynamic polarization curves (a) and Nyquist plots (b) for Mg alloy substrate coated and uncoated with DLC film in $3.5 \% \mathrm{NaCl}$ solution at room temperature.

bond elongating the carbon chain [Eq. (4)]. The subsequent dehydrogenation leads to the formation of DLC, as presented in the Eq. (5).

$$
\begin{aligned}
& \mathrm{Mg}-\mathrm{CH}_{3}+\mathrm{CH}_{3}^{+} \rightarrow \mathrm{Mg}-\mathrm{CH}_{2}-\mathrm{CH}_{3}+\mathrm{H}^{+} \\
& \mathrm{Mg}-\mathrm{CH}_{2}-\mathrm{CH}_{2}-\mathrm{CH}_{2}-\mathrm{CH}_{2}-\mathrm{CH}_{2}-\mathrm{CH}_{3} \\
& \quad \rightarrow \mathrm{Mg}-\mathrm{CH}=\mathrm{CH}-\mathrm{CH}=\mathrm{CH}-\mathrm{CH}_{2}-\mathrm{CH}_{3}+n \mathrm{H}_{2}
\end{aligned}
$$

Sreejith et al. propose that bond could also be formed between a carbon and other adjacent carbon on the substrate surface, thus propagating the chain both along the substrate and away from the substrate. ${ }^{23}$ Meanwhile, they use lower voltages $(80-300 \mathrm{~V})$ by decreasing the electrode separation and so increasing the solution conductance to deposit DLC films, allowing larger current densities to flow. In our work, addition of $\mathrm{KNO}_{3}$ to electrolyte can improve the solution conductance and account for as large as $333 \mathrm{~mA} / \mathrm{cm}^{2}$ current density to flow. Therefore, a high deposition rate can be obtained.

Figure 6(a) shows the polarization curves of Mg alloy substrate coated and uncoated with DLC film in $3.5 \% \mathrm{NaCl}$ solution at room temperature. In the figure $E\left(\mathrm{mV}_{\mathrm{SCE}}\right)$ represents the potential and the $\mathrm{i} / \mathrm{mAcm}^{-2}$ represents the current density. A significant improvement of the substrate in corrosion resistance due to the DLC film was evidenced by a shift of the whole polarization curve towards the region of lower current density and higher potential.

Furthermore, it can be seen that the corrosion potential of electrodeposited DLC film on Mg substrate shifted positively by $-300 \mathrm{mV}$ compared with $\mathrm{Mg}$ substrate. This effect from the DLC film is similar to the effect of electrodeposited DLC film on Ti substrate, reported by T. M. Manhabosco et al. in which the corrosion potential difference between the DLC film electrodeposited from acetonitrile onto $\mathrm{Ti}$ and $\mathrm{Ti}$ substrate is about 
$-400 \mathrm{mV} .^{20}$ The difference in corrosion potential shift from both films is probably attributable to their thickness and compactness.

Figure 6(b) shows the Nyquist plots for $\mathrm{Mg}$ alloy substrate coated and uncoated with DLC film in $3.5 \% \mathrm{NaCl}$ solution at room temperature. The high-frequency impedance arc is attributed to the processes occurring at the electrode-electrolyte interface. The diameter of the arc can be regarded as the polarization resistance $\left(\mathrm{R}_{\mathrm{t}}\right)$, which denotes the kinetic resistance to ion transfer at the electrode-solution boundary. The size of DLC film-coated Mg alloy substrate is much larger than that of DLC film-uncoated one, thereby indicating again that the corrosion resistance is improved by formation of DLC film, in consistent with the result of polarization curves in Fig. 6(a).

\section{Conclusions}

A simple method, cathodic micro-arc discharge, was developed to prepare diamond-like carbon films in aqueous solutions. Raman spectra and XPS analysis demonstrated that the films are typically diamond-like carbon clearly. SEM observation shows that the DLC films were quite uniform. Potentiodynamic polarization tests and electrochemical impedance spectroscopy (EIS) indicated that the corrosion resistance of the Ni substrate was markedly improved by DLC films.

\section{Acknowledgments}

The work is financially supported by the Chinese National Nature Science Foundation (Grant. 51172102/E020801\&21203085) and promotive research fund for young and middle-aged scientists of Shandong Province (doctor fund) (BS2011CL011).

\section{References}

1. B. L. Mordike and T. Ebert, Mater. Sci. Eng., A, 302, 37 (2001).

2. H. Hoche, C. Rosenkranz, A. Delp, and M. M. Lohrengel, Surf. Coat. Tech., 193, 178 (2005).

3. H. Hoche, C. Blawert, E. Broszeit, and C. Berger, Surf. Coat. Tech., 193, 223 (2005).

4. G. Song, A. L. Bowles, and D. H. Stjohn, Mater. Sci. Eng., A, 366, 74 (2004).

5. Y. L. Song, Y. H. Liu, S. R. Yu, X. Y. Zhu, and Q. Wang, Appl. Surf. Sci., 254, 3014 (2008).

6. A. Ghasemi, V. S. Raja, C. Blawert, W. Dietzel, and K. U. Kainer, Surf. Coat. Tech., 202, 3513 (2008).

7. R. Gadow and D. Scherer, Surf. Coat. Tech., 151-152, 471 (2002).

8. J. D. Majumdar, R. Galun, B. L. Mordike, and I. Manna, Mater. Sci. Eng., A, 361, 119 (2003).

9. J. Liang, P. Wang, L. T. Hu, and J. C. Hao, Mater. Sci. Eng., A, 454-455, 164 (2007).

10. H. Q. Sun, Y. N. Shi, and M. X. Zhang, Surf. Coat. Tech., 202, 2859 (2008).

11. Z. M. Liu and W. Gao, Surf. Coat. Tech., 200, 5087 (2006).

12. M. X. Zhang and P. M. Kelly, J. Mater. Res., 17, 2477 (2002).

13. W. B. Lee, C. Y. Lee, M. K. Kim, J. I. Yoon, Y. M. Yoen, and S. B. Jung, Compos. Sci. Technol., 66, 1513 (2006).

14. J. Robertson, Mater. Sci. Eng. Rep., 37, 129 (2002).

15. N. Yamauchi, K. Demizu, N. Ueda, T. Sone, M. Tsujikawa, and Y. Hirose, Thin Solid Films, 506-507, 378 (2006).

16. J. Choi, J. Kim, S. Nakao, M. Ikeyama, and T. Kato, Nucl. Instrum. Meth., B, 257, 718 (2007).

17. T. Pauporté, J. Finne, A. Kahn-Harari, and D. Lincot, Surf. Coat. Tech., 199, 213 (2005).

18. T. Paulmier, J. M. Bell, and P. M. Fredericks, Thin Solid Films, 515, 2926 (2007).

19. W. Han, Y. He, D. Wang, R. Xue, and W. Gao, Chin. J. Rare Metals., 28, 622 (2004).

20. T. M. Manhabosco and I. L. Muller, Appl. Surf. Sci., 255, 4082 (2009).

21. W. He, R. Yu, H. Wang, and H. Yan, Carbon, 43, 2000 (2005).

22. J. Tsukada, H. Zanin, L. C. A. Barbosa, G. A. da Silva, H. J. Ceragioli, A. C. Peterlevitz, R. F. Téofilo, and V. Baranauskasa, J. Electrochem. Soc., 159, D159 (2012).

23. K. Sreejith, J. Nuwad, and C. G. S. Pillai, Appl. Surf. Sci., 252, 296 (2005). 